\title{
La intermunicipalidad en el AMBA. Análisis de las experiencias de asociativismo Región Metropolitana Norte y Consorcio de Municipios del Conurbano Sur
}

Intermunicipality in the Metropolitan Area of Buenos Aires. An Analysis of twoexperiences of municipal associativism

Fernando J. Rubino

Maestrando en Gobierno Local (UNQ). Universidad Nacional de Quilmes Instituto de Estudio y Administración Local. Municipalidad de Quilmes. rubinofj@gmail.com

Fecha de recepción:

8.9.20

Fecha de aceptación:

1.1.21

\section{Resumen}

Este artículo presenta un análisis de los dos casos más significativos de asociativismo intermunicipal del Área Metropolitana de Buenos Aires. La revisión del génesis de los proyectos, su agenda y dinámica de trabajo, el alcance de sus políticas, las relaciones políticas que implicaron y las causas del declive permiten reflexionar sobre las posibilidades que este arreglo institucional ofrece como herramienta de gestión para abordar la cuestión metropolitana en la Provincia de Buenos Aires. La formalización de los consorcios, la delimitación del alcance y objetivos, las políticas de promoción y financiación de los niveles superiores de gobierno y la participación de actores no gubernamentales estratégicos para el desarrollo son claves para pensar intermunicipalidades que se sostengan en el tiempo. 
Palabras clave: asociativismo intermunicipal consorcios de desarrollo - gestión local asociada áreas metropolitanas - Buenos Aires.

\begin{abstract}
This article focuses on the two most significant cases of intermunicipal associativism in the Metropolitan Area of Buenos Aires. The review of the genesis of the projects, their agenda and work dynamics, the scope of their policies, the political relations they implied and the causes of decline, allow us to think over the possibilities that this institutional arrangement presents as a management tool for the metropolitan issue in Buenos Aires. The formalization of the consortia, the delimitation of their scope and objectives, the promotion and financing policies by the higher levels of government and the participation of strategic, non-governmental actors for development, are the keys to think intermunicipalities that can be sustained over the time.
\end{abstract}

Key-words: intermunicipal associativism - development consortiums-/ local associative management - metropolitan areas - Buenos Aires.

\title{
Introducción
}

El Área Metropolitana de Buenos Aires, conformada por la Ciudad Autónoma de Buenos Aires (CABA) y los 24 municipios del Gran Buenos Aires (GBA) a su alrededor, es la mayor en términos demográficos (con una población casi 10 veces superior a la segunda, el Área Metropolitana de Córdoba) y socio-económicos de las 24 áreas metropolitanas de Argentina (Pírez 2007). Operan en esta región cuatro niveles de gobierno: Gobierno Nacional, Gobierno de la CABA, Gobierno de la Provincia de Buenos Aires y los gobiernos locales (municipales) del GBA. Estas cuestiones, sumadas a los casi 15 millones de habitantes de la región que representan el 37\% de la población nacional, dan cuenta del peso específico y la complejidad para la coordinación de las iniciativas estatales en esta megaciudad, que no es una unidad administrativa. La fragmentación, desconexión, solapamiento y desigual nivel de impacto de las políticas públicas son problemas muy frecuentes. 
Sin embargo, debe mencionarse que las discusiones sobre el problema metropolitano son más habituales en la esfera técnica que en la agenda de discusión política. El presente contexto en 2020 de pandemia mundial a raíz del COVID-19 introdujo una novedad al poner al AMBA en el centro de la escena, tal vez como nunca antes, por ser la región argentina con mayor circulación del virus. Se dieron entonces situaciones de articulación muy importantes (en este caso en materia de política sanitaria) entre los distintos niveles de gobierno de la región. Hoy la esfera política, los medios de comunicación y la ciudadanía hablan del AMBA nominándola de esta manera, algo inédito, y haciendo referencia al "problema metropolitano". Por este motivo entendemos pertinente el análisis y la difusión de políticas públicas tengan a este escenario por objeto, como las que aquí se presentan.

Históricamente se han discutido dos tipos de abordaje para este gigante: la creación de una autoridad metropolitana supramunicipal -que requeriría modificaciones institucionales)-, interjurisdiccionales ${ }^{1}$ (enfoque top-down en términos de análisis de políticas públicas), y las propuestas de intermunicipalidad de las que trata este artículo, donde de manera voluntaria y coordinada los municipios cooperan horizontalmente para darse políticas locales a escala metropolitana (enfoque bottom-up). ${ }^{2}$

En las últimas décadas los gobiernos locales han ido adquiriendo una relevancia cada vez mayor en la definición de políticas públicas destinadas a mejorar las condiciones de vida de las poblaciones y el desarrollo de los territorios. El principio de subsidariedad, que indica que la mejor instancia de gobierno para resolver problemas es la más cercana al ciudadano, ganó importancia a nivel mundial, promoviéndose procesos de descentralización globales. Los municipios entonces asumieron una mayor cantidad de competencias y funciones. En el caso argentino, este fenómeno se conjugó con la descentralización forzada por la crisis política y económica de fines de la década de 1990, cuando el estado central distribuyó el impacto de la crisis hacia los niveles subnacionales, y los estados provinciales y municipales se encontraron con la ausencia de recursos necesarios para cumplimentar las funciones que la ciudadanía les demandaba. En este contexto histórico-político surge el asociativismo intermunicipal en la Provincia de Buenos Aires.

La primera etapa va desde 1993 a 1999, caracterizada por la creación de los llamados corredores o consorcios productivos en el interior de la provincia, que tenían por objetivo principal la promoción del desarrollo económico local. El cambio de gobierno producido en 1999 y la agudización de la crisis político-institucional en 2001 marcaron el fin de estas primeras experiencias asociativas. A comienzos de la década del 2000 comienzan a darse nuevas experiencias de consorcios bonaerenses. Esta segunda etapa tuvo la característica de localizarse en el Área Metropolitana de Buenos Aires y de transitar su apogeo en un período de recuperación económica, hacia mediados de esa década. La primera de ellas es la Región Metropolitana Norte (RMN), integrada por los municipios de Vicente López, San Fernando, San Isidro y Tigre. La otra experiencia de esta etapa es el 
Consorcio de Municipios del Conurbano Sur (COMCOSUR), creado en el 2004 por los municipios de Almirante Brown, Quilmes, Florencio Varela, Berazategui, Avellaneda, Lomas de Zamora y Lanús. Esto representó el Norte y el Sur del Conurbano Bonaerense organizados en dos asociaciones con diferencias tanto en el aspecto socio-económico y demográfico del territorio, en la composición y pertenencia política, como en el grado de institucionalización alcanzado y la forma y dinámica de sus agendas de trabajo. Sin embargo, lo común es que ambas iniciativas ingresaron en un declive hacia fines de la misma década en que fueron creadas, hasta quedar sin funcionamiento real.

Este artículo propone un análisis comparado de estas dos iniciativas de intermunicipalidad en el AMBA. Para ello, además de una revisión del estado del arte, se llevaron adelante entrevistas con informantes clave, tanto del ámbito político como del técnico-académico, que participaron o investigaron ambas asociaciones, para relevar en profundidad las experiencias y buscar las diferencias, similitudes, fortalezas y debilidades del proceso. ${ }^{3}$ Esperamos con este trabajo contribuir a la discusión sobre la potencialidad de este arreglo institucional como un instrumento para abordar la problemática metropolitana, y sobre las condiciones a futuro del asociativismo intermunicipal en la Provincia de Buenos Aires.

\section{Definición y repaso de la intermunicipalidad en la Provincia de Buenos Aires}

Cravacuore (2016) define al asociativismo intermunicipal como el "fenómeno de articulación de un conjunto de gobiernos locales interconectados e interdependientes con el fin de ejecutar colectivamente una o más políticas públicas bajo un principio de coordinación horizontal y sin jerarquía entre las unidades estatales que intervienen" (p. 23), que tomaremos para dar cuenta del carácter de política desde abajo (Fagundez, 2018) que es constitutivo de este tipo de arreglo institucional.

En líneas generales existe consenso en el campo académico respecto a los siguientes rasgos constitutivos del asociativismo intermunicipal: voluntad local para su creación, cooperación entre los gobiernos municipales, búsqueda de resolución de problemas comunes y búsqueda de maximización de recursos y capacidades institucionales. Una cuestión objeto de algunas discrepancias entre los expertos es la formalización legal de las asociaciones: mientras que para unos es una condición necesaria, otros la consideran importante pero no constitutiva de este tipo de arreglos institucionales. En los casos de análisis que presentamos en este artículo se ven las dos formas, lo que a nuestro criterio muestra que este aspecto es relativo a los efectos prácticos del funcionamiento de las asociaciones.

Como se mencionó, es a partir de 1990 con el proceso de reforma del estado y descentralización que los municipios empiezan a darse procesos de asociación voluntaria, lo que da cuenta del aspecto reciente que presenta este instrumento para las políticas 
públicas como disciplina de estudio -tanto en Argentina como en toda América Latina-. Si bien se registran experiencias de consorcios municipales en nuestro país a partir de la década de 1960, las mismas fueron del tipo de políticas supramunicipales -la primera de ellas, el "Plan de Prefectura del Gran Rosario" entre 1967 y 1976- e impulsadas desde-arriba, es decir, impuestas por niveles superiores de gobierno con baja o ninguna participación de los municipios en la planificación e implementación.

La intermunicipalidad se mostraba en los noventa como una herramienta que podía contribuir tanto a mitigar los efectos de la descentralización sin recursos impulsada en esa década, como también aportar a la superación de algunos problemas derivados de la falta de actualización del criterio territorial con que se erigió el diseño político-institucional argentino en el siglo XIX. Esta arquitectura, funcional a los problemas que el país necesitaba resolver en ese siglo, arrastra en la actualidad una serie de problemas que requerirían de reformas que el sistema político argentino no termina de consensuar para encarar: delimitación en unidades administrativas que no siempre reflejan las relaciones socioeconómicas de un territorio (como el caso metropolitano, en general, y del AMBA en particular), fragmentación, desigual distribución de recursos, desconexión entre las políticas públicas, distribución competencial difusa entre niveles del estado, solapamiento y duplicación de iniciativas por falta de coordinación, todo lo cual redunda en un nivel de impacto disímil de las políticas públicas.

Entre la década de 1990 y los albores del nuevo siglo, la cooperación intermunicipal se presentaba también como opción para afrontar el problema del tamaño de los gobiernos locales argentinos, que Mónica Iturburu (2001) caracteriza como inframunicipalismo y refiere a la gran cantidad de gobiernos locales existentes en el país, muchos de población reducida y con capacidad institucional débil para afrontar las nuevas agendas locales. Este fenómeno, que anteriormente se encontraba invisibilizado, salió a la superficie en este período de descentralización competencial. ${ }^{4}$

Entendemos entonces que el tamaño de los gobiernos locales, sumado a los efectos de la recesión, son las razones por las que el primer período de cooperación intermunicipal sucede en este momento y se localiza principalmente en el interior del país, con la característica de orientarse en la búsqueda del desarrollo económico local y la optimización del gasto público que permitiera mitigar las cada vez más debilitadas capacidades institucionales municipales.

Durante esta etapa también se dio un importante proceso de apoyo desde los niveles superiores de gobierno a la intermunicipalidad, sobre todo desde las provincias. ${ }^{5}$ Las políticas de promoción del asociativismo tienen como característica que los gobiernos provinciales intervienen pero reconociendo un interés de los gobiernos locales en asociarse para la implementación de políticas en conjunto, y acompañan o impulsan las iniciativas a través de la facilitación del marco normativo, la revisión de la distribución competencial o el financiamiento de las estructuras de gestión de las asociaciones (siempre 
respetando la dinámica desde abajo y con los municipios liderando las iniciativas, por lo que no deben confundirse con los proyectos centralizados de regionalización). En la Provincia de Buenos Aires, el novedoso proceso asociativo cumple con este análisis y las primeras iniciativas generan mecanismos de apoyo por parte del estado provincial.

Con el fin de promover y coordinar estas iniciativas y el cooperativismo, y en el marco más general de políticas provinciales orientadas al desarrollo económico local como estrategia para mitigar este período de ajuste del gasto público, caída de la actividad económica y retroceso en los indicadores de producción, empleo y pobreza, el gobierno bonaerense creó en 1992 el Instituto Provincial de Acción Cooperativa (IPAC). Este organismo tuvo por objetivo trabajar en la financiación de las estructuras administrativas de los consorcios y la adecuación del difuso marco legal de los mismos, llegando a promover la sanción de la Ley 12288 de 1999 sobre la temática que introdujo avances normativos en cuanto al control de gastos, habilitando al cobro de un gravamen para sustentar su funcionamiento e impulsando al ejecutivo provincial a promocionar las asociaciones (Cravacuore, 2011), al reemplazar al artículo $43^{\circ}$ de la Ley Orgánica Municipal, originalmente previsto para los consorcios de provisión de servicios públicos.

El cambio de gobierno producido en 1999 -cuando Fernando de la Rúa asumió la presidencia de la República y el peronista Carlos Ruckauf sucedió al también peronista Eduardo Duhalde en la gobernación de la provincia de Buenos Aires- y la profunda crisis económica del 2001, que derivó en una crisis político-institucional (y fiscal en lo que respecta a la administración estatal), modificaron el escenario para la intermunicipalidad bonaerense. En una primera instancia, el cambio de autoridades del IPAC implicó que el organismo discontinuara las políticas de promoción, con lo que sin financiamiento para las estructuras de los consorcios su actividad se redujo considerablemente. Luego del año 2001 y la inestabilidad institucional que lo signó, ${ }^{6}$ las autoridades al frente de la provincia disolvieron el IPAC, lo que terminó por diluir este primer proceso asociativista bonaerense, desapareciendo los consorcios creados. Sin embargo, la innovación que implicó y el dinamismo en la materia de este período ejercería influencia en el cambio de década y de siglo para que comenzara una serie de nuevas experiencias, en un escenario diferente. 


\section{Región Metropolitana Norte}

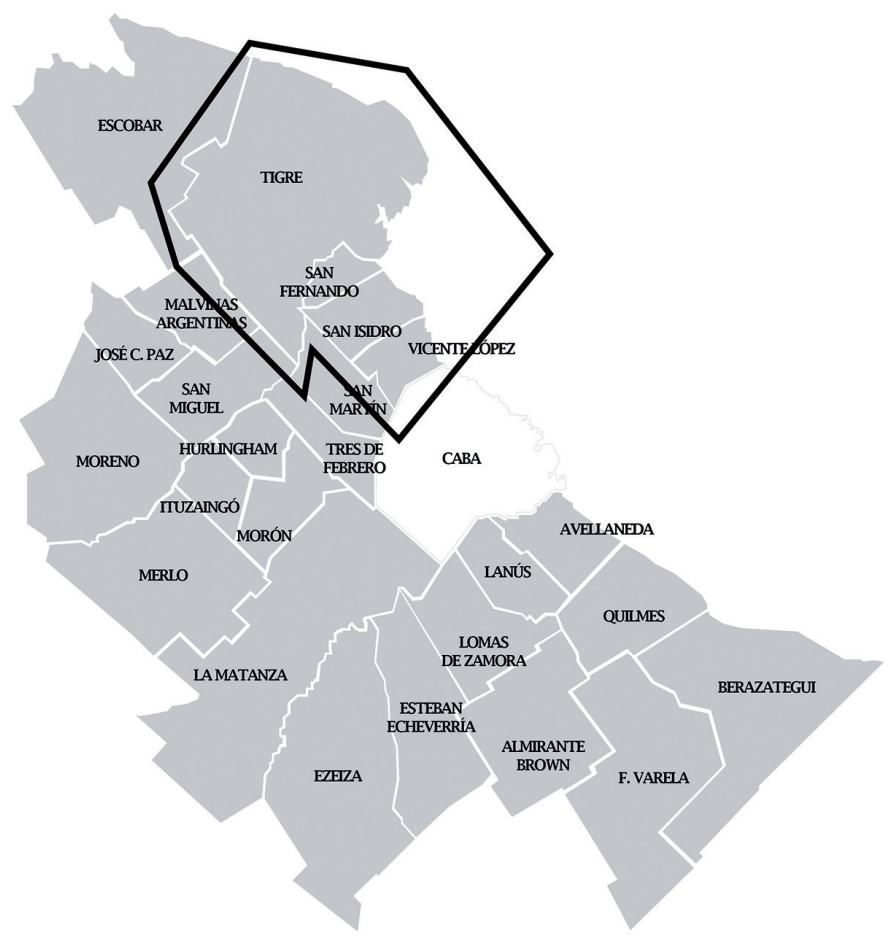

En el año 2000 los municipios de Vicente López, San Isidro, San Fernando y Tigre conforman la Región Metropolitana Norte (RMN), la primera intermunicipalidad surgida por iniciativa desde-debajo en el AMBA, formalizada mediante la firma de un acta constitutiva el 10 de Abril. Según el Censo Nacional de Población de 2010 la población de esta región es de 1.101.919 habitantes, $11 \%$ de la población total del Conurbano Bonaerense (24 partidos del Gran Buenos Aires) y ocupa una superficie total de $1324,08 \mathrm{~km}^{2}$, de los cuales $257 \mathrm{~km}^{2}$ son de territorio continental y el resto territorio de islas bajo la jurisdicción de los partidos de Tigre y San Fernando. Estos municipios del corredor norte del conurbano bonaerense, eje costero, tienen una ubicación estratégica ya que los atraviesa la Autopista Ing. Pascual Palazzo, traza inicial de la Ruta Nacional No 12 y que empalma a su vez con la Ruta Nacional No 14 (también denominada Ruta Nacional del Mercosur), uniendo al puerto de Buenos Aires con las provincias de Entre Ríos, Corrientes y Misiones, y continuando hacia los pasos fronterizos con Uruguay y Brasil. La región posee una infraestructura vial de rutas y caminos privilegiada en cuanto a su conexión con la capital del país. En la RMN se localiza también un aeropuerto internacional (San Fernando) y de diferentes puertos. 
El Producto Bruto Geográfico (PBG) acumulado de los municipios de la RMN representaba, de acuerdo a las cifras más actualizadas disponibles, 20,6\% del total del conurbano, y el PBG per cápita casi duplicaba la media regional (ICO-UNGS 2008). Los municipios que integran este grupo se encuentran entre los que muestran valores más favorables en términos socioeconómicos de los 24 partidos que conforman el Gran Buenos Aires. ${ }^{7}$

La media del indicador de hogares con Necesidades Básicas Insatisfechas (NBI) es 6,4\%, siendo casi 3 puntos inferior a la media general del conurbano que es de 9,2\%. El único de estos municipios que se encuentra por encima de la media es Tigre con 11\%, pero hay que contemplar que en gran parte se debe a que tiene una importante población isleña con hogares sin acceso a algunos servicios públicos incluidos en el índice NBI. Se observa en el Cuadro $N^{\circ} 1$ la relación inversa entre NBI y PBG en la RMN, debida en gran medida a Vicente López y San Fernando, los municipios con mejores indicadores de este tipo en todo el conurbano.

Cuadro N¹: Indicadores socioeconómicos de los municipios de la RMN

\begin{tabular}{|l|l|l|l|l|l|}
\hline Municipio & Superficie $\mathbf{( k m} 2)$ & Habitantes & Hogares & \% de hogares con NBI & PBG per cápita \\
\hline San Fernando & 877,08 & 163240 & 49384 & 8,6 & 26761 \\
\hline San Isidro & 48 & 292878 & 97213 & 3,7 & 37338 \\
\hline Tigre & 360 & 376381 & 108558 & 11 & 19077 \\
\hline Vicente López & 39 & 269420 & 99286 & 2,4 & 49867 \\
\hline TOTAL & $\mathbf{1 3 2 4 , 0 8}$ & $\mathbf{1 1 0 1 9 1 9}$ & $\mathbf{3 5 4 4 4 1}$ & $\mathbf{6 , 4}$ & $\mathbf{3 2 5 9 7}$ \\
\hline
\end{tabular}

* A precios de productor, año 2008

Fuente: Elaboración propia en base a datos ICO-UNGS e INDEC, Censo Nacional 2010

La actividad industrial motoriza económicamente esta región, representando el sector secundario de la economía (industria y construcción) el 51,5\% del PBG, seguido por el sector terciario (servicios, principalmente comercio, actividades inmobiliarias y recreación/ turismo) con el 48,4\%. Esta misma condición socioeconómica favorable se puede ver en la comparación de la proporción de población con categoría ocupacional patrón/jefe + trabajador profesional por cuenta propia (INDEC, Censo Nacional de Población 2010).

En líneas generales, los municipios de la RMN muestran indicadores por encima de la media en materia de poder adquisitivo. En esta dimensión destacan San Isidro yVicente López, ubicados entre los municipios del AMBA con mayor presencia de jefes/patrones/profesionales independientes sobre el total de la población, y mostrando valores muy cercanos a los de la CABA (Cuadro No 2). 
Cuadro N²: RMN. Población (\%) con categoría ocupacional patrón/jefe+ trabajador profesional por cuenta propia

\begin{tabular}{|l|l|}
\hline Municipio & $\begin{array}{l}\text { \% de población patrón/ } \\
\text { jefe }+ \text { TCP profesional }\end{array}$ \\
\hline San Fernando & 9 \\
\hline San isidro & 18 \\
\hline Tigre & 9 \\
\hline Vicente López & 17 \\
\hline CABA & 16 \\
\hline
\end{tabular}

Fuente: elaboración propia en base a datos INDEC, Censo Nacional 2010

Como se mencionó en la introducción, las experiencias de intermunicipalidad de la década anterior en el interior de la provincia generaron un antecedente que fue tomado por las nuevas asociaciones con el cambio de década. A su vez, según los entrevistados para el presente artículo, en la RMN influyó también la experiencia internacional, particularmente con el caso de Francia, donde el problema del inframunicipalismo es severo y los consorcios fueron ampliamente promovidos para mitigarlo. Los intendentes Ricardo Ubieto (Tigre) y Gustavo Posse (San Isidro) visitaron la región francesa de El Havre con el fin de conocer el modelo aplicado -también puesto en práctica en Italia y España-.

El Acta Constitutiva de la Región Metropolitana Norte se propuso objetivos amplios y diversos, orientados al desarrollo local y regional: “ (...) interés común para el progreso de las comunidades de los cuatro Municipios", "Promover la cultura política del diálogo y el consenso, entre los ciudadanos, el Gobierno Nacional, el Gobierno Provincial y los Gobiernos Municipales", "Proponer la integración y coordinación de las políticas públicas municipales, provinciales y nacionales en el ámbito de la Región Metropolitana Norte", "Realizar una planificación regional para impulsar el desarrollo sustentable de nuestras ciudades", entre otros objetivos. ${ }^{8}$

Igualmente destacable es la inclusión de algunos objetivos con un nivel de especificidad mayor, como propiciar la reforma constitucional pendiente en la Provincia de Buenos Aires para consagrar la autonomía municipal como lo indica la reforma a la Constitución Nacional de 1994, o la representación de la ciudadanía ante las empresas de servicios públicos del espectro nacional o provincial. Algunos de los objetivos también referían a cuestiones más de escala regional que de sumatoria de problemas locales, como "el uso de los puertos y riberas, el desarrollo de la región de islas", características de esos municipios, o la voluntad de unificar criterios urbanísticos. Cabe mencionar en este punto que los funcionarios que impulsaron la RMN eran conscientes que existía 
en los ciudadanos de sus municipios una pertenencia a la región, o una identidad de "zona norte" relacionada con cuestiones históricas o culturales, y trataban también de capitalizar políticamente esta condición, basando entonces los consensos políticos en la fuerte convivencia territorial de la población (Esteban y Rossi, 2003). De acuerdo a Cravacuore (2011) esta cuestión identitaria, sumada a la dinámica de trabajo, contribuyó a hacer prontamente de la RMN un actor político reconocid.

También hay coincidencia en que uno de los objetivos principales buscados con la creación de la RMN fue el ejercicio del denominado "poder de lobby". ${ }^{9}$ Esto es, ganar escala acumulando capital político para poder negociar en mejores condiciones, sobre todo con el poder político provincial. Al momento de la creación de este consorcio el gobierno nacional estaba en manos de la alianza electoral liderada por la Unión Cívica Radical (UCR), y la gobernación de la Provincia de Buenos Aires correspondía al peronismo (Partido Justicialista, PJ). La RMN tenía una composición política no homogénea en sus jefes comunales, pero con mayoría opositora dentro del mapa político bonaerense de la época (Cuadro $N^{\circ} 3$ ).

Cuadro $\mathbf{N}^{\mathbf{0}}$ 3: Intendentes $\mathrm{RMN}$

\begin{tabular}{|l|l|l|l|}
\hline Municipio & Intendente (fecha de creación) & Mandato/s & Recambio \\
\hline San Isidro & Gustavo Posse (UCR) & $1999-$ actual & - \\
\hline San Fernando & Gerardo Amieiro (PJ) & $1995-2011$ & Luis Andreotti (PJ-FpV) \\
\hline Tigre & Ricardo Ubieto (vecinalismo) & $1979-1983 / 1987-2006$ & Sergio Massa (PJ-FpV). 2007. \\
\hline Vicente López & Enrique García (UCR) & $1987-2011$ & Jorge Macri (PRO) \\
\hline
\end{tabular}

Elaboración propia

Vicente López y San Isidro venían siendo gobernados por el radicalismo desde el retorno de la democracia en 1983, el primero con el mismo jefe comunal desde 1987 y el segundo con el intendente recién asumido en 1999, pero heredando el armado político hegemónico de su padre Melchor Posse en el distrito, cuyo primer mandato como intendente fue en 1958, repitiendo a partir de 1983 y cumpliendo 5 períodos en total. En Tigre era hegemonía el vecinalismo de Acción Comunal desde 1987, con la particularidad de un intendente que ya había ocupado ese cargo en el gobierno de la última dictadura militar (1979-1983) y luego a través de elecciones desde 1987.Y en el caso de San Fernando, la larga continuidad también se daba, pero desde el lado del peronismo, que gobernaba el distrito también desde 1983 (aunque Amieiro lo hacía desde 1995). ${ }^{10}$ En síntesis, todos los mandatarios iban por al menos su segundo mandato a excepción de Gustavo Posse, que sin embargo por las características mencionadas, también representaba la continuidad de un mismo proyecto político local. 
La asociación adoptó la siguiente forma: "El Consorcio 'Región Metropolitana Norte” se regirá por medio de un Consejo Ejecutivo formado por los Intendentes Municipales de los cuatro Partidos, y contará con un consejo Técnico y de Planeamiento integrado por los distintos secretarios de cada Municipio". El Consejo Ejecutivo dictaba el reglamento, ejercía la representación del municipio y marcaba la agenda de trabajo, que operativizaban los equipos técnicos en las comisiones temáticas. A pesar del conocimiento y del nivel de confianza que se tenían entre sí los intendentes, la distinta pertenencia política hizo que se adopte el criterio de toma de decisiones unánime en la RMN. Los cuatro mandatarios tenían que estar de acuerdo entre sí, evitándose la posibilidad de realizar acuerdos "chicos" entre los integrantes de la mesa que pudieran fracturar las relaciones y limitando la intromisión de las distintas "terminales" políticas de cada intendente en la asociación. Esto, si bien disminuía la cantidad de proyectos a desarrollarse, dotaba a los mismos de un volumen político importante, y mostraba hacia afuera un esfuerzo en materia de cooperación horizontal (Cravacuore, 2011).

El gobierno provincial mostró su reconocimiento a la iniciativa: el entonces vicegobernador Felipe Solá participó del acto de lanzamiento, y mantuvo luego como gobernador reuniones de trabajo, apoyando la provincia iniciativas propuestas desde la región como la construcción de una alcaldía o la delimitación jurisdiccional de las islas del delta, un conflicto de larga data entre los municipios de San Fernando y Tigre. ${ }^{11}$ A su vez, el gobierno nacional, a través de la Subsecretaría de Asuntos Municipales, mostró su apoyo intercediendo para que las empresas de servicios públicos -la mayoría de ellas concesionadas en esa época, fruto de las políticas de descentralización y privatización de la década anterior-, sus organismos de control y organismos con alcance en la región como el CEAMSE (Coordinación Ecológica Área Metropolitana Sociedad del Estado) reconocieran a la RMN como interlocutora válida. Estas articulaciones permitieron trabajar en programas de recolección diferenciada de residuos o articular con el Ente Administrador de Bienes Ferroviarios en la cesión de terrenos no utilizados por los ramales de trenes.

Los movimientos en conjunto por parte de los intendentes, la difusión permanente de las actividades y reuniones mensuales (mediante campañas de comunicación dirigidas tanto a la ciudadanía como a la dirigencia política), profundizaron la legitimación del consorcio, que también trabajó en la toma de posición frente a determinadas cuestiones que hacían al interés regional (Cravacuore, Ilari,Villar, 2004): la ya mencionada petición por la consagración de la autonomía municipal bonaerense, el rechazo a que la CABA, a través del CEAMSE- organismo en el cual los municipios bonaerenses no tienen representación- enterrara residuos en la zona norte, la oposición al aumento de las tasas de créditos del Banco Provincia a los municipios, y el apoyo a propuestas de descentralización desde la provincia hacia los municipios, como la gestión de los registros civiles y el cobro de deudas del Impuesto Inmobiliario y Patentes del Automotor. 
En materia de articulación de gestión, la RMN avanzó en acuerdos con el gobierno de la CABA y el Registro de la Propiedad Automotor para la emisión de constancias de infracciones de tránsito y deudas de patentes, para la percepción de las multas por infracciones de tránsito en el ámbito de la región, en compras conjuntas de materiales de vialidad, insumos de salud, equipamiento informático haciendo uso del poder de negociación ganado con la escala de la intermunicipalidad, en planificar coordinadamente el ordenamiento del tránsito - por ejemplo, en la continuidad de los sentidos de dirección de las arterias que se prolongan en otro municipio (Fagundez, 2007)-, en un proyecto de producción en conjunto de medicamentos, y en la promoción del comercio exterior a través de la creación de una Comisión de Comercio Exterior de la Región y en la certificación de calidad de las PYME de la región.

El funcionamiento de este primer consorcio metropolitano bonaerense ingresó en un declive hacia mediados de la década del 2000, hasta quedar finalmente inactivo. El punto de inflexión lo marcó el recambio de actores entre los mandatarios comunales. Por un lado, el intendente de Tigre Ricardo Ubieto (uno de los que más había impulsado el proyecto en sus inicios), falleció en noviembre 2006 siendo reemplazado por su jefe de gabinete.Además, en las elecciones de 2007 el triunfo en Tigre del peronista Sergio Massa, que hasta ese momento se desempeñaba como director ejecutivo nacional de la ANSES (Administración Nacional de la Seguridad Social) en el gobierno del presidente Néstor Kirchner (20032007), terminó con la hegemonía vecinalista en el municipio e implicó un quiebre en términos de confianza para el resto de los intendentes. ${ }^{12}$ El período 2007-2011 fue de muy baja actividad en comparación con el inicial, y las elecciones del 2011 terminaron de consolidar la inactividad casi total al asumir Jorge Macri, por el partido Propuesta Republicana (PRO), y Luis Andreotti por el peronismo en San Fernando. En este último período las discusiones, ya sin el mismo ímpetu, pasarían por la incorporación de nuevos municipios a la asociación como San Martín y Escobar, para lo cual no hubo consenso, y el proceso devino en la conformación de la nueva Región Metropolitana Norte 2 en 2016 con los municipios de Escobar, Tigre, San Fernando, Pilar, Campana y Malvinas Argentinas. Esta nueva iniciativa es la única intermunicipalidad activa actualmente, pero dado que es un objeto de estudio distinto al que presentamos, que se trata de una experiencia reciente y que su nivel de actividad es bajo, no se incluye en el presente artículo.

Es frecuente señalar que la RMN dejó pendiente la formalización legal: el consorcio funcionó siempre con el convenio firmado por los intendentes como acta constitutiva, nunca llegó a redactarse un estatuto. El marco legal vigente en los inicios de la RMN tampoco estaba pensado para este tipo de iniciativas, por lo que desde la asociación se eligió el camino de la legitimación por la vía política a medida que se iba ganando dinámica y apoyos, en vez de la formalización (a pesar de tener que sortear algunos inconvenientes para el reconocimiento por parte de otros organismos públicos). La falta de una estructura burocrática propia del consorcio también es señalada en las 
investigaciones sobre el tema, ya que la dinámica de trabajo quedaba subsumida a los recursos financieros y humanos que cada municipio, en medio de su propia gestión interna, pudiera asignar al consorcio. En este punto cabe mencionar que la no generación de una estructura burocrática también fue parte de los acuerdos iniciales, dados en el marco de la profunda crisis que atravesaba el país.

\section{Consorcio de Municipios del Conurbano Sur}

En el año 2004, en un contexto político distinto al del inicio de la RMN, con el país empezando un proceso de crecimiento económico y estabilización institucional bajo la presidencia de Néstor Kirchner, se conforma el Consorcio de Municipios del Conurbano Sur (COMCOSUR) con los municipios de Almirante Brown, Quilmes, Florencio Varela, Berazategui, Avellaneda, Lomas de Zamora y Lanús. El 1 de Julio de ese año los mandatarios comunales de estos municipios, en ese momento gobernados en su totalidad por el peronismo, firmaron el convenio de cooperación.

La población del consorcio, de 3,3 millones de personas, representa 33\% del total del Conurbano Bonaerense (Censo Nacional de Población 2010), dato que muestra el peso específico de esta asociación. Pensado al principio para integrar a los municipios del eje ferroviario (y costero) que une a la ciudad de Buenos Aires con La Plata (capital provincial), finalmente se resolvió ampliar a todos los municipios del Conurbano Sur para aprovechar el volumen político de la populosa tercera sección electoral, principal bastión del peronismo en la provincia (aunque no agrupó la totalidad de los 19 distritos que la integran). ${ }^{13}$

En estos territorios sureños es mucho más alta la cantidad de barrios en situación de vulnerabilidad social, que en su mayoría se componen por villas de emergencia y asentamientos precarios, siendo esta una de las dimensiones que muestran la alta concentración de pobreza existente en estos municipios (aunque con diferencias entre sí como los casos de Lanús y Avellaneda que muestran valores bajos).${ }^{14}$ La presencia de hogares con indicadores NBI se encuentra 0,3 puntos por encima de la media del conurbano bonaerense. El PBG, si bien representa el 30,1\% del total del conurbano (mostrando el peso específico territorial que tiene este consorcio), desagregado por habitante es menor a la media regional. ${ }^{15}$ 
Mapa N²: Consorcio de Municipios del Conurbano Sur

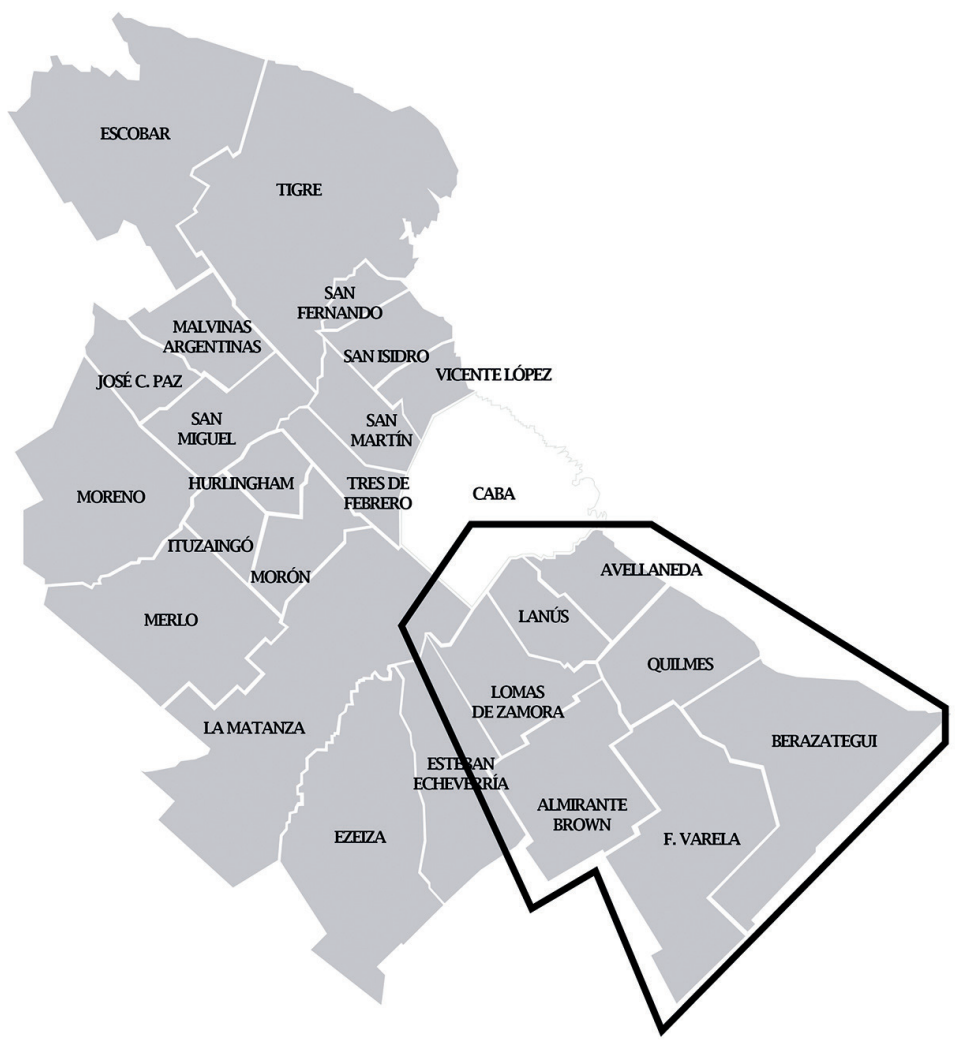

Cuadro $\mathbf{N}^{\circ}$ 4: Indicadores socioeconómicos de los municipios del COMCOSUR

\begin{tabular}{|l|l|l|l|l|l|}
\hline Municipio & $\begin{array}{l}\text { Superficie } \\
(\mathbf{k m} \mathbf{)}\end{array}$ & Habitantes & Hogares & $\begin{array}{l}\text { \% de hogares con } \\
\text { NBI }\end{array}$ & PBG per cápita \\
\hline Almirante Brown & 129,33 & 552902 & 156918 & 10,5 & 11413 \\
\hline Avellaneda & 52,48 & 342677 & 113142 & 5,8 & 28225 \\
\hline Berazategui & 221,01 & 324244 & 93164 & 10,4 & 14662 \\
\hline Florencio Varela & 189,9 & 426005 & 113135 & 17 & 9138 \\
\hline Lanús & 48,35 & 459263 & 149594 & 5 & 16021 \\
\hline Lomas de Zamora & 87,3 & 616279 & 188844 & 8,9 & 17899 \\
\hline Quilmes & 91,49 & 582943 & 177110 & 9,2 & 16134 \\
\hline TOTAL & $\mathbf{8 1 9 , 8 6}$ & $\mathbf{3 3 0 4 3 1 3}$ & $\mathbf{9 9 1 9 0 7}$ & $\mathbf{9 , 5}$ & $\mathbf{1 5 8 6 5}$ \\
\hline
\end{tabular}

Fuente: elaboración propia en base a datos ICO-UNGS e INDEC, Censo Nacional de Población 2010 
En esta región la actividad industrial supo ser un factor de desarrollo local, llegando a atraer a mediados del siglo XX corrientes de migraciones internas. Este sector se resintió fuertemente con las políticas de desindustrialización del modelo neoliberal imperante entre mediados de la década del 1970 hasta fines de los noventa, siendo una de las razones de la alta pobreza estructural. El PBG por sectores indica que hoy el sector terciario, de comercio y servicios, es el que más riqueza produce con el 58,7\% del total; el secundario con el $41 \%$, sigue siendo significativo, traccionado no sólo por la industria sino también por una importante actividad de la construcción. Avellaneda es el único municipio donde el perfil industrial sigue siendo más fuerte que el de comercio y servicios (58,5\%); FlorencioVarela y Berazategui, por su parte, integran el llamado cordón verde del AMBA, con una importante actividad agrícola a través de huertas pertenecientes a pequeños emprendedores o al sector asociativo -muchas de ellas gestionadas por organizaciones sociales y/o políticas-.

En la comparación de la proporción de población con categoría ocupacional patrón/ jefe + trabajador profesional por cuenta propia se ve cómo este grupo de municipios muestran valores en el orden de la mitad de los de la CABA.

Cuadro N5: COMCOSUR. Porcentaje de población con categoría ocupacional patrón / jefe + trabajador profesional por cuenta propia

\begin{tabular}{|l|l|}
\hline Municipio & $\begin{array}{l}\text { \% de población patrón/ } \\
\text { jefe }+ \text { TCP profesional }\end{array}$ \\
\hline Avellaneda & 5 \\
\hline Berazategui & 6 \\
\hline Florencio Varela & 6 \\
\hline Lanús & 9 \\
\hline Lomas de Zamora & 7 \\
\hline Quilmes & 8 \\
\hline CABA & 16 \\
\hline
\end{tabular}

Fuente: elaboración propia en base a datos INDEC, Censo Nacional 2010

A diferencia de la RMN, la génesis del COMCOSUR no incluyó influencias de políticas asociativas del exterior. Según las fuentes entrevistadas, tampoco hubo un análisis de la experiencia del norte del conurbano, que ya llevaba cuatro años funcionando, ya fuera para evaluar su impacto o para la comparación en términos políticos, para replicarla en el Sur. Se barajó también al principio la idea de seguir el modelo de mancomunidad para la prestación concreta de servicios públicos -muy común en el modelo europeo de asociaciones, pero con menos opciones por el marco jurídico-institucional argentino donde no es posible que los municipios cedan funciones a una intermunicipalidad-; 
finalmente se optó por el más amplio modelo comarcal (también llamado de entes microrregionales) definido por la búsqueda colectiva del desarrollo local ${ }^{16} \mathrm{en}$ cualquiera de sus dimensiones (Cravacuore, 2006).

Algunos de los objetivos del consorcio, definidos en su estatuto y que plasma el modelo elegido, fueron: "Potenciar las políticas de estado trazadas por los Intendentes signatarios del COMCOSUR propendiendo a un mayor crecimiento armónico regional; generar un compromiso solidario entre los municipios miembros, tendiente al desarrollo conjunto (...); defender los intereses comunes de los habitantes de los Partidos miembros del Consorcio, definiendo estrategias consensuadas de desarrollo económico, local y regional; promover la resolución conjunta de problemáticas comunes que hacen a: cuestiones ambientales de la región tales como: tratamiento de efluentes, saneamiento de agua y cloacas, disposición final de residuos; como también compras conjuntas de bienes y servicios, mediaciones ante controversias limítrofes entre jurisdicciones. planificación estratégica de redes viales, construcción de calles o túneles comunes, gestión asociada tendiente a ampliar los servicios en salud, compra de medicamentos a mayor escala, coordinación regional respecto del tratamiento de la inseguridad de los habitantes del COMCOSUR, en coordinación con los órganos competentes, etcétera.". ${ }^{17}$

En cuanto a la agenda de trabajo, se incluyeron temáticas vinculadas a los problemas urbanos propios de la región del consorcio como el saneamiento de cuencas hídricas ${ }^{18}$ y proyectos vinculados a mejorar las magras capacidades institucionales financieras de sus municipios, como compras conjuntas de insumos de salud o baja de los costos de la disposición final de los residuos sólidos urbanos. El Hospital El Cruce-Dr. Néstor Kirchner, nosocomio de alta complejidad inaugurado en 2007, de gran relevancia para el sistema de salud de los municipios de Florencio Varela, Berazategui, Almirante Brown y Quilmes, también fue un proyecto discutido en las reuniones de trabajo del COMCOSUR. ${ }^{19}$ Además, se trabajó en la búsqueda de financiamiento externo, la horizontalidad de normativas de tránsito, la unificación de criterios para la habilitación de industrias y comercios, en negociaciones con la empresa estatal AySA para la extensión de la red de cloacas, en la difusión de actividades del consorcio, y la toma de posición en común en temas como la siempre determinante coparticipación secundaria de la provincia a los municipios, o la demanda de más cupos para programas sociales, entre otras iniciativas. En el año 2007 se firmó un convenio con la ciudad de Buenos Aires, para trabajar en el sistema vial, que no llegó a implementarse. 
Cuadro N6: Intendentes COMCOSUR

\begin{tabular}{|l|l|l|l|}
\hline Municipio & Intendente (fecha de creación) & Mandato/s & Recambio \\
\hline Almirante Brown & Manuel Rodríguez (PJ) & $2003-2007$ & Darío Giustozzi (PJ-FpV) \\
\hline Avellaneda & Baldomero A. de Olivera (PJ) & $1991-1999 / 2003-2009$ & Jorge Ferraresi (PJ-FpV) \\
\hline Berazategui & Juan José Mussi (PJ) & $1987-1994 / 2003-2010$ & Juan Patricio Mussi (PJ-FpV) \\
\hline Florencio Varela & Julio Pereyra (PJ) & $1991-2017$ & Andrés Watson (PJ-FpV) \\
\hline Lanús & Manuel Quindimil (PJ) & $1973-1976 / 1983-2007$ & Darío Díaz Pérez (PJ-FpV) \\
\hline Lomas de Zamora & Jorge Rossi (PJ) & $2003-2009$ & Martín Insaurralde (PJ-FpV) \\
\hline Quilmes & Sergio Villordo (PJ) & $2003-2007$ & Francisco Gutiérrez (PJ-FpV) \\
\hline
\end{tabular}

Elaboración propia

Sin embargo, lo que motivó casi de manera exclusiva la conformación del consorcio fue la voluntad de sumar fuerzas, crear sinergia, para negociar en mejores condiciones con los poderes provincial y nacional, apoyándose en el nivel de confianza que se tenían los intendentes entre sí, producto del conocimiento por los años al frente de sus municipios en la mayoría de los casos, y la pertenencia a la estructura del peronismo bonaerense, en su totalidad. Como se ve en el cuadro $N^{\circ} 6$, Avellaneda, Berazategui, Florencio Varela y Lanús tenían al frente de sus municipios a intendentes de larga trayectoria que habían construido hegemonías políticas locales, y fueron fuertes impulsores del proyecto. ${ }^{20}$

El COMCOSUR se estructuró de la siguiente manera: un Consejo de Administración, ${ }^{21}$ integrado por los intendentes, un Consejo de Planificación (órgano técnico, compuesto mayoritariamente por los secretarios de los municipios que ejecutaban los lineamientos políticos definidos en el Consejo de Administración)un Consejo Asesor y una Auditoría Interna.

Una de las notas características de este consorcio fue la rigurosa dinámica de trabajo, considerada imprescindible para lograr la coordinación necesaria dado el tamaño del consorcio. Los intendentes se reunían estrictamente cada tres semanas, teniendo una reunión cerrada entre ellos primero y abriéndola luego a los equipos técnicos, que estaban organizados mediante comisiones sectoriales y temáticas. ${ }^{22}$ Las reuniones contemplaban también una instancia pública, muchas veces con conferencias de prensa y a la que se extendían también invitaciones especiales, como funcionarios del gobierno provincial (principalmente ministros, aunque en alguna oportunidad asistió Daniel Scioli, gobernador de la PBA entre 2007 y 2015), o los concejales de cada distrito. ${ }^{23}$ La toma de decisiones también se inclinó hacia la unanimidad para los intendentes, aunque se mantuvo la mayoría simple para las comisiones de planificación. Esta última estaba integrada por dos representantes de cada municipio que se reunían semanalmente, y para dinamizar las comisiones de trabajo existía la figura de una coordinación administrativa, cuyo 
salario era asumido por la Municipalidad de Avellaneda. El Consejo Asesor se diseñó como un ámbito para que participaran instituciones no gubernamentales de la zona que fueran actores clave en el desarrollo local (Cravacuore, Ilari y Villar 2004), aunque solo fue integrado por la Universidad Nacional de Quilmes y la Universidad Tecnológica de Avellaneda, y la articulación respondió más a la iniciativa individual de actores vinculados al proyecto que a una cooperación institucional. ${ }^{24}$

El carácter político del consorcio, así como le otorgó muchísimo volumen en su período de mayor auge, también marcó los tiempos al principio y al final de la iniciativa. De acuerdo a Fagundez (2018), el COMCOSUR empieza a funcionar con fuerte dinamismo después de las elecciones del 2005, donde el peronismo bonaerense resolvió su interna en las elecciones legislativas de ese año con el triunfo por amplio margen del Frente para la Victoria. ${ }^{25}$ Los jefes comunales apoyaron distintas listas, y es después de estas elecciones cuando el consorcio comienza su período de mayor intensidad, conducido por los actores que salieron fortalecidos del proceso. Tal fue la influencia del COMCOSUR en términos políticos durante ese período, que en 2006 fue disparador de la sanción de la nueva normativa sobre consorcios de gestión y desarrollo. La Ley 13580, que reemplazó a la Ley 12288 de 1999, subsanó algunos grises que se encontraban en la ley anterior en materia de control y fiscalización de los entes intermunicipales, siendo considerada uno de los mayores logros de este consorcio (junto con la formalización alcanzada en la sanción del citado estatuto en el año 2007).

El COMCOSUR se inició en un momento en que la totalidad de los municipios estaban gobernados por los mismos sectores del peronismo (con anclaje en la década anterior), y su funcionamiento comenzó a disminuir cuando las gestiones fueron cambiando, entrando en un ocaso paulatino a partir de 2007 (más allá de esporádicos anuncios de relanzamiento). Si bien, como se mostraba en el Cuadro $\mathrm{N}^{\circ}$ 6, la gestión de estos municipios continuó en su totalidad dentro del peronismo, algunos intendentes fueron reemplazados por adversarios internos que luego desconfiaban del consorcio por considerar que habían apoyado a sus rivales electorales. ${ }^{26}$

Por otro lado, a partir del 2008 la agenda política comienza a ser ocupada fuertemente por las cuestiones nacionales, quedando relegados los temas vinculados al desarrollo local y regional y esmerilando la rutina de trabajo que se había alcanzado. ${ }^{27}$ Además, el contexto de crecimiento económico del momento facilitaba el diálogo y los acuerdos entre estos municipios, el gobierno provincial y (principalmente ahora) el nacional, que había comenzado una etapa de recentralización de la política pública con fuerte presencia de sus organismos en el territorio y generando una relación fluida tanto con los gobiernos locales como con organizaciones sociales. ${ }^{28}$ Este contexto desalentó, por no resultar ya esencial para la negociación o la obtención de recursos, la estrategia de asociación desde abajo que había sido motivadora de este y otros consorcios bonaerenses. 
Al igual que la RMN, la iniciativa no fue disuelta, pero se encuentra en inactividad. En la última década hubo intentos de dotarlo nuevamente de funcionamiento, pero no pasaron de reuniones eventuales que no alcanzaron el dinamismo del período descripto.

\section{Conclusiones y aportes para la discusión de la intermunicipalidad metropolitana 2020 .}

Al introducir este artículo señalamos que se esperaba contribuir a la discusión de la potencialidad que este arreglo institucional presenta como instrumento para abordar la problemática metropolitana, y sobre las condiciones a futuro del mismo. Se torna indispensable entonces preguntarse porqué ambos casos presentados fueron experiencias discontinuadas, a pesar de haber transitado períodos de intensa actividad. Más aun teniendo en cuenta que en la década que transcurrió entre el declive de los dos consorcios y la actualidad, se intentó ponerlos nuevamente en funcionamiento pero no se pudo superar la etapa del voluntarismo inicial, para pasar luego a la intermitencia y/o a la inactividad total nuevamente.

En páginas anteriores presentamos indicadores socioeconómicos de los municipios que integran ambos asociaciones intermunicipales, que ilustran las diferencias que existen entre el norte y el sur del Conurbano Bonaerense -algo que también puede hacerse extensivo al AMBA dado que en la CABA se registran equivalentes diferencias socioeconómicas entre los barrios del norte y el sur de la ciudad. Asimismo se mostraron diferencias sociodemográficas, que hablan de distintas escalas, con una población más numerosa en los municipios sureños que, agregamos, tienen una variación intercensal de población mayor: comparando los datos de los censos nacionales de población, entre 1980 y 2010 la población de los municipios del COMCOSUR se incrementó un 34\%, mientras que en la RMN el crecimiento fue del $20 \%$.

Vamos a comparar ahora algunos aspectos financieros, una de las dimensiones que muestran las capacidades con que cuentan los municipios, siguiendo la definición de capacidad estatal como "La habilidad real y potencial que deben poseer los estados y sus agencias específicas para articular intereses sectoriales, decidir un rumbo y tomar decisiones, superando de manera exitosa las restricciones que plantea el entorno institucional.” (Completa 2017). 
Cuadro N²: Presupuestos comparados RMN y COMCOSUR

\begin{tabular}{|l|l|l|l|l|}
\hline Municipio & Consorcio & Presupuesto 2017 & $\begin{array}{l}\text { Presupuesto } \\
\text { por habitante }\end{array}$ & $\begin{array}{l}\text { \% de recursos } \\
\text { propios }\end{array}$ \\
\hline San Fernando & RMN & $\$ 2.195 .619 .793$ & $\$ 13.450$ & 72,93 \\
\hline San Isidro & RMN & $\$ 4.870 .607 .774$ & $\$ 16.630$ & 61,00 \\
\hline Tigre & RMN & $\$ 4.864 .443 .571$ & $\$ 12.924$ & 70,26 \\
\hline Vicente López & RMN & $\$ 4.897 .476 .293$ & $\$ 18.178$ & 68,54 \\
\hline Almirante Brown & COMCOSUR & $\$ 3.309 .771 .684$ & $\$ 5.986$ & 37,54 \\
\hline Avellaneda & COMCOSUR & $\$ 5.728 .001 .803$ & $\$ 16.715$ & 91,38 \\
\hline Berazategui & COMCOSUR & $\$ 1.948 .401 .475$ & $\$ 6.009$ & 37,17 \\
\hline Florencio Varela & COMCOSUR & $\$ 2.435 .761 .181$ & $\$ 5.718$ & 28,01 \\
\hline Lanús & COMCOSUR & $\$ 3.895 .213 .013$ & $\$ 8.481$ & 44,55 \\
\hline Lomas de Zamora & COMCOSUR & $\$ 5.046 .752 .196$ & $\$ 8.189$ & 49,16 \\
\hline Quilmes & COMCOSUR & $\$ 4.170 .771 .851$ & $\$ 7.155$ & 46,07 \\
\hline
\end{tabular}

Elaboración propia en base a datos Honorable Tribunal de Cuentas de la Provincia de Buenos Aires

Puede apreciarse que los municipios de la RMN cuentan con recursos bastante más significativos, tanto en cuanto al presupuesto por habitante como al porcentaje de recursos propios, que otorgan a los gobiernos locales una cierta autonomía financiera respecto a los gobiernos provinciales y nacionales. Esta mayor capacidad financiera se desprende de las condiciones socioeconómicas estructurales de cada territorio, que impactan en la recaudación de los municipios. Mientras que la media del presupuesto por habitante de la RMN es de \$15.272, para el COMCOSUR es de \$8.030. El porcentaje de recursos propios muestra la misma relación: los municipios del Sur, a excepción de Avellaneda, son dependientes de las transferencias de los niveles superiores de gobierno, mientras que los del Norte muestran una autonomía significativamente mayor.

El nivel de institucionalización de este tipo de iniciativas suele ponerse también como variable de análisis en los casos de asociativismo, para medir el desarrollo o profundización del proyecto de un consorcio intermunicipal. Si bien sería lógico que a mayores capacidades institucionales se alcance un nivel de formalización mayor, vimos que el COMCOSUR se desarrolló algo más en este terreno, con un estatuto que lo constituyó como persona jurídica de derecho pleno, y algunos funcionarios técnicos que desempeñaban tareas exclusivamente para el consorcio, generando una (pequeña) estructura propia. La RMN se mantuvo sólo como una coordinación en red de los gobiernos municipales (principalmente de sus intendentes). 
Por último se expusieron las diferentes composiciones políticas, con homogénea pertenencia al peronismo en los municipios del sur y una composición heterogénea, pero mayoritariamente radical en el norte -representada por la UCR en la época de inicio de la RMN y actualmente como integrante de la Alianza Cambiemos-. Este anclaje político no sólo marcó una diferencia de composición hacia dentro de cada consorcio, sino de posicionamiento para con los gobiernos de la PBA y la Nación: el COMCOSUR tuvo siempre, en el período analizado, relaciones políticas dentro del oficialismo gobernante, mientras que la RMN ha ido modificando su condición ya que empezó con un gobierno peronista en la provincia y una alianza liderada por el radicalismo en la nación, y continuó luego con el peronismo en el gobierno nacional.

Sin embargo, en este conjunto de variables (condicionantes socioeconómicos, demográficos, capacidades financieras, distintos niveles de formalización, composición político-partidaria) en el que podemos agrupar una dimensión socio-económica, estructural, y otra político-institucional, que diferencian a ambas asociaciones, no hemos encontrado un impacto gravitante en cuanto al desarrollo de los procesos. Vamos a examinar ahora los paralelismos encontrados, con el objetivo de indagar en las causas del declive de las experiencias y reflexionar sobre las posibilidades de la intermunicipalidad como arreglo institucional en la actualidad.

La mayor regularidad encontrada en ambos casos es la presencia, al inicio del consorcio, de gobiernos que tenían una continuidad de varios años al frente de cada municipio. En la RMN esta condición se cumplió con unanimidad -considerando a Gustavo Posse como continuador de la misma gestión en San Isidro- y en el COMCOSUR con cuatro de los siete intendentes. Este mismo aspecto, que contribuyó a las relaciones de confianza que se mostraron necesarias entre los mandatarios para iniciar los proyectos, y a una mayor visión sobre cuestiones estratégicas o de largo alcance que otorga la experiencia acumulada en la gestión pública, fue a su vez el mismo que hizo que cada intermunicipalidad no pudiera continuar en las instancias de recambio de autoridades por los distintos periodos electorales, con la dinámica que había alcanzado. Surge acá un elemento importante a tener en cuenta para pensar el asociativismo intermunicipal en la Provincia de Buenos Aires hoy: en 2016 se sancionó una reforma política que impide la reelección indefinida tanto de los jefes comunales como de los concejales, por lo que no se volverán a repetir escenarios de mandatarios con tantos períodos al frente de sus municipios. Alcanzar una mayor institucionalización de las asociaciones, con mecanismos, roles, alcances y objetivos formalizados, se erige como una opción que puede hacer que las relaciones de confianza dadas por el tiempo sean menos relevantes a los efectos de la gestión asociada. ${ }^{29}$ Para ello los niveles superiores de gobierno son clave, a través de la implementación de políticas de promoción de los consorcios que financien sus estructuras, ${ }^{30}$ sus gastos operativos, que contribuyan a la legitimidad, como se intentó con el Instituto Provincial de Acción Cooperativa tutelando a los corredores productivos del interior. Sin embargo, no es sencilla la implementación de este apoyo, ya que muchas veces las asociaciones desde abajo generan desconfianza en los gobiernos provinciales y nacional. 
En ambos casos pudimos observar también otras características que tienen o tuvieron, en general, las experiencias asociativas en el país: las dificultades de la gestión asociada -la coordinación en red que modifica la jerarquía burocrática tradicional, la relación radial entre los distintos niveles de gobierno, particularmente fuerte en el AMBA con presencia activa de cuatro tipos de gobierno- es dificil de armonizar con la existencia de los vínculos de competencia que muchas veces se dan entre distritos para facilitar el flujo de los recursos públicos de los poderes provinciales o nacionales, sumado a la propia competencia política de mandatarios que aspiran a ocupar lugares en esos niveles de gobierno. La coordinación entre política y territorio también es de difícil convivencia con la visión de las gestiones locales dentro de los límites estrictos del territorio -sin tener en cuenta que muchos fenómenos tienen origen en instancias superiores o repercuten en entornos regionales, lo que conlleva a diagnósticos locales erróneos-, aportando mayor complejidad a las posibilidades del asociativismo intermunicipal. En los casos que presentamos, fue (como se dijo) la relación entre los mandatarios lo que facilitó, al menos durante el período en que los consorcios funcionaron plenamente, la superación de estas dificultades. Una mayor institucionalización, a través de la promoción de las asociaciones por parte de los niveles superiores de gobierno, también puede contribuir a la superación de estos problemas comunes.

Otro punto encontrado ha sido el de los objetivos muy generales, dotados además de una expectativa inicial optimista que con el correr del tiempo se diluye debido a que los resultados de las asociaciones no son de corto plazo. Surge también de la opinión de los entrevistados la necesidad de revisar este aspecto, ya que dificulta la planificación formal (ausente en ambos casos) y la sostenibilidad de las iniciativas. La figura de las mancomunidades se presenta como opción a tener en cuenta, ya que esta modalidad se acota a la unión de municipios para la realización de una actividad o la prestación de un servicio público que evita la coordinación de una agenda amplia de temas y el involucramiento de la multiplicidad de actores que demanda el modelo comarcal utilizado en la RMN y el COMCOSUR (Cravacuore 2011). Existen experiencias en esta línea en municipios del interior bonaerense que llevan más de dos décadas de funcionamiento, entre las que se pueden mencionar el convenio de compras conjuntas para insumos hospitalarios de General Pinto que funciona desde 1995, o el Consorcio del Centro de la Provincia de Buenos Aires (COCEBA), que involucra a los municipios de Olavarría, Azul, Laprida y Daireaux que en el año 2000 se unieron para presentarse ante el PAMI como prestadores de servicios de salud. ${ }^{31}$ Uno de los entrevistados sugirió, para pensar esta forma más acotada de asociarse, tener en cuenta a la producción agrícola (y social) de los municipios de Berazategui y Florencio Varela, que si bien no alcanza los niveles que se encuentran en el interior de la provincia, genera el 34\% del PBG del sector primario del Conurbano Bonaerense, con lo que podría ser un punto de asociación en la búsqueda de la soberanía alimentaria para abastecer los proyectos sociales de los municipios metropolitanos, dado el presente contexto de contracción económica. 
Del mismo modo encontramos en la comparación de las experiencias, que no fueron políticas de las que la ciudadanía se haya apropiado, por desconocimiento de la potencialidad de la asociación municipal: "incomprensión social sobre el mecanismo asociativo" (Cravacuore 2016). En ninguno de los dos casos estudiados se contempló la participación de actores territoriales de la sociedad civil estratégicos para el desarrollo local, como los representantes del comercio y la industria, la educación, la cultura u otros, reforzando la desconexión entre el ente y la ciudadanía. ${ }^{32}$ Tampoco los órganos legislativos locales han tenido participación significativa o continuada. Reforzar este aspecto puede contribuir a visibilizar a los consorcios y a mejorar su legitimidad e institucionalización, mitigando la dependencia de la coyuntura política y la necesidad de dotar de grandes estructuras burocráticas a las iniciativas.

En suma, se ha visto que a pesar de las dificultades que presenta la implementación de esta modalidad de gestión asociada, y de la necesidad de su revisión, sigue siendo una herramienta posible y necesaria para abordar la cuestión metropolitana en el AMBA y poder generar consensos y coordinación en esa región tan fragmentada en términos político-administrativos pero con problemas que no reconocen los límites de los municipios ni la división competencial entre los niveles de gobierno (como sucede con la pandemia epidemiológica del coronavirus COVID-19). Para ello, las relaciones entre los jefes comunales como vínculo fundante y sostenedor de las asociaciones intermunicipales desde abajo necesitan ser complementadas con otras iniciativas de política pública, para que no ocupen la centralidad de los procesos. Entendemos que los aportes vertidos en el presente trabajo (fomentar la institucionalización, las políticas de promoción, evaluar otras formas de asociación y mejorar la participación ciudadana mediante actores estratégicos de la sociedad civil), sumados a que este tipo de iniciativas no necesitan de reformas institucionales profundas como sí los proyectos de autoridades supramunicipales, pueden contribuir a repensar las estrategias de asociativismo intermunicipal, en la senda de la mejora de las condiciones de vida de la población y la equidad territorial, en un contexto en que la problemática metropolitana en la Provincia de Buenos Aires ocupa un lugar central en la agenda de discusión pública. 
${ }^{1}$ La Coordinación Ecológica del Área Metropolitana (CEAMSE), la Corporación del Mercado Central de Buenos Aires y la Autoridad de Cuenca Matanza Riachuelo (ACUMAR) son organismos diseñados de acuerdo a este criterio. En ellas los gobiernos municipales bonaerenses carecen de intervención

${ }^{2}$ Reforzando la autonomía constitucionalmente reconocida en la reforma de la Constitución Nacional de 1994 con la inclusión del artículo 123: "Cada provincia dicta su propia Constitución, conforme a lo dispuesto por el Art. 5 asegurando la autonomía municipal y reglando su alcance y contenido en el orden institucional, político, administrativo, económico y financiero". Es pertinente señalar para los casos que presentamos que la Provincia de Buenos Aires es una de las tres provincias argentinas que todavía no reconocieron esta autonomía en sus textos constitucionales, junto con Mendoza y Santa Fe.

${ }^{3}$ Estas entrevistas se llevaron a cabo durante los meses de julio y agosto 2020.

${ }^{4}$ En Argentina hay un total de 2391 de los cuales sólo 1129 son municipalidades, mientras que el resto no alcanza esa jerarquía (comisiones de fomento, juntas rurales, juntas de gobierno, comisiones municipales, delegaciones de fomento y comunas). Además, en más de la mitad de estos gobiernos viven menos de 5000 habitantes (Cravacuore, 2014).

${ }^{5}$ También estuvo presente en la agenda nacional con el Programa de Microrregiones Patagónicas, que identificó para potenciar 17 microrregiones.

${ }^{6} \mathrm{La}$ volatilidad de esos días llevó además de la renuncia del presidente De La Rúa y a la del gobernador Ruckauf que pasó a desempeñarse como Ministro de Relaciones Exteriores del gobierno nacional provisional, asumiendo el entonces vicegobernador Felipe Solá la gobernación de la provincia de Buenos Aires.

${ }^{7}$ Separamos acá la categoría GBA del AMBA ya que la comparación de estos municipios con la CABA es muy difícil de mensurar tanto en términos socioeconómicos como demográficos y político-institucionales, a pesar de conformar (como se dijo) una misma zona urbana.

${ }^{8}$ Acta Constitutiva Región Metropolitana Norte - Ordenanza No 2253/00 Municipalidad de Tigre.

${ }^{9}$ https://www.pagina12.com.ar/2000/00-04/00-04-11/pag15.htm

${ }^{10}$ Este mandatario había promovido en la campaña por su reelección en 1999 la creación de un consorcio intermunicipal regional.

${ }^{11} \mathrm{https}$ //www.clarin.com/ediciones-anteriores/sola-reune-intendentes-region-metropolitana-norte_0_HyLlm1nyRKx. html

${ }^{12}$ Posse continúa al frente de San Isidro, mientras que Amieiro y García dejaron su lugar en 2011.

${ }^{13}$ La 3ra sección representa el 35\% del padrón bonaerense, que a su vez alcanza el 37\% del padrón nacional. Comprende 19 partidos que aportan 18 diputados provinciales y 9 senadores provinciales. Gran parte del peso político de esta sección es capitalizado por La Matanza, municipio del Oeste del GBA que supera el millón y medio de habitantes y con quien, en términos políticos, el COMCOSUR buscó disputar puertas adentro del peronismo. ${ }^{14}$ La diferencia entre villas y asentamientos es que las primeras son ocupaciones irregulares de tierra urbana vacante que responden a la suma de prácticas individuales, diferidas en el tiempo y dan cuenta de su precaria materialidad, con alta densidad poblacional y hacinamiento. Los asentamientos, en cambio, son trazados urbanos producto de la acción colectiva de toma que tienden a su regularización futura, sus pobladores no lo perciben como solución habitacional transitoria, sino como una mejora a mediano plazo.

${ }^{15} \$ 17.546$ es la media de los 24 partidos GBA mientras que $\$ 15865$ la de los municipios del COMCOSUR. 16 “(..:) propendiendo al desarrollo local sustentable, como premisa de justicia social”. Estatuto del Consorcio de Municipios del Conurbano Sur. La inclusión del concepto de justicia social muestra la pertenencia al peronismo del consorcio.

${ }^{17}$ Estatuto del Consorcio de Municipios del Conurbano Sur (2007).

${ }^{18} \mathrm{La}$ cuenca de los arroyos que atraviesan los partidos del conurbano sur presenta gran concentración de barrios populares radicados sobre el camino sirga, con población en situación de vulnerabilidad social muy afectada por problemas socioambientales como inundaciones frecuentes y/o suelo degradado por contaminación industrial.

${ }^{19}$ Es un nodo de la red de salud de la región, integrada por los hospitales Mi Pueblo de Florencio Varela, Evita Pueblo de Berazategui, Arturo Oñativia de Almirante Brown, Hospital de Agudos Dr. Isidoro Iriarte de Quilmes, Hospital Subzonal Especializado Materno Infantil Dr. Oller de San Francisco Solano (Quilmes), Hospital Zonal General de Agudos Lucio Meléndez de Adrogué (Almirante Brown), Hospital Subzonal de rehabilitación Motriz Dr. José María Jorge de Burzaco (Almirante Brown) y el Centro Integral de Salud, Diagnóstico y Rehabilitación "Julio Méndez” de Bernal” (Quilmes).

${ }^{20}$ La experiencia del intendente Julio Pereyra como presidente de la Federación Argentina de Municipios fue muy influyente en el proyecto COMCOSUR.

${ }^{21}$ ARTÍCULO $7^{\circ}$ : La representación del COMCOSUR será ejercida por un Consejo de Administración que estará integrado por los Señores Intendentes de los Municipios miembros del Consorcio. Será el órgano rector 
de Gobierno y Administración. Los cargos dentro del Consejo serán elegidos inicialmente en Asamblea por simple mayoría. El período de duración en sus cargos será de doce (12) meses y la renovación de los cargos se efectuará en forma ascendente, comenzando a partir del último vocal y de manera escalonada hacia los cargos superiores. Estatuto del Consorcio de Municipios del Conurbano Sur.

${ }^{22}$ Una que tuvo gran dinámica fue la de telecomunicaciones, porque coincidió con el período de masificación de la telefonía celular.

${ }^{23}$ De acuerdo a un informante clave los ministros "no la pasaban muy bien" debido a que las demandas de siete intendentes juntos de la populosa 3ra sección electoral se "hacían sentir".

${ }^{24}$ El Dr. Daniel Cravacuore, docente investigador de la UNQ que también se desempeñaba en ese momento al frente del Instituto de Desarrollo Local en la Municipalidad de Florencio Varela y como asesor del intendente, cumplió un rol fundamental tanto en esta articulación institucional como en la planificación del COMCOSUR en general.

${ }^{25}$ El duhaldismo y el kirchnerismo se presentaron por separado, con el sello del PJ el primer sector y como Frente para la Victoria el segundo. Cristina Fernández de Kirchner se impuso por más de 25 puntos a Hilda González de Duhalde, marcando el fin de la

${ }^{26}$ El caso de la interna más fuerte tal vez haya sido en Quilmes: si bien Sergio Villordo no se había comprometido activamente con el COMCOSUR, Francisco Gutiérrez lo hizo menos, creyendo que los otros mandatarios seguían manteniendo vínculos con su predecesor, quien seguía teniendo un bloque representativo de dirigentes en el municipio y le complicaba la gestión (según relató informante clave). También hubo cambio de mandatarios en Almirante Brown y Lanús.

${ }^{27}$ Según informantes clave, durante ese año las reuniones del COMCOSUR quedaron eclipsadas por el conflicto derivado de la Resolución 125, que intentó cobrar mayores aranceles al sector primario agroexportador. Este enfrentó fuertemente al gobierno nacional para resistir la medida, mediante lock-out patronales que generaron desabastecimiento, y un prolongado clima de inestabilidad institucional. Las movilizaciones eran constantes, de ambos lados, y parte importante de la base de apoyo del kirchnerismo estuvo en el peronismo de la Provincia de Buenos Aires, por lo que no había lugar para la agenda local.

${ }^{28}$ Tanto la política social mediante organismos como ANSES, PAMI, los ministerios de Desarrollo Social (PBA y Nación) y la cartera nacional de Trabajo, Empleo y Seguridad Social, como el financiamiento de la obra pública: el Ministerio de Planificación, Inversión Pública y Servicios de la Nación se encontraba fuertemente activo financiando obras de infraestructura en territorio bonaerense.

${ }^{29}$ Hay coincidencia en este punto por parte de los actores entrevistados para el presente artículo. Pero no se habla de una institucionalización como la formalización legal alcanzada por el COMCOSUR con la firma de su estatuto, sino que permita visibilizar y legitimar a los consorcios en el mapa de la política y la administración pública regional. Se mencionó como propuesta el fortalecimiento del rol de los técnicos en los consorcios, para conformar una burocracia propia que sea ejecutora de los lineamientos que emanen de la conducción.

30 "Los recursos dinamizan los procesos" expresó uno de los informantes clave. Esto se relaciona además a que la falta de financiamiento suele impedir que los mandatarios comunales ubiquen a los consorcios entre los temas prioritarios de sus gestiones.

${ }^{31}$ El Instituto Nacional de Servicios y Jubilados (INSSJP), conocido como PAMI, es un organismo público nacional que gestiona prestaciones de salud y sociales para el $80 \%$ de la población de adultos mayores del país. ${ }^{32}$ Más allá de las universidades nacionales que como se explicó, se vinculó más a iniciativas individuales que institucionales. 


\section{Referencias bibliográficas}

Abal Medina, Juan Manuel (h.) (2009) "La cooperación intergubernamental en Argentina: mejor Estado y mejor democracia”. Reforma y Democracia 44:203-224.

Cadaval, M. y Carames, L. (2006) "Una aproximación a los modelos de intermunicipalidad” En: Urban Public Economics Review, núm. 6, 2006, pp. 33-67. Universidad de Santiago de Compostela (España).

Completa, Enzo (2017) “Capacidad estatal: ¿Qué tipo de capacidades y para qué tipo de Estado?”. POSTData, Revista de Reflexión y Análisis Político 22 (1) 111-140.

Cravacuore, Daniel (2016) "El asociativismo intermunicipal" en: D. Cravacuore y A. Chacón, eds. El asociativismo intermunicipal en América Latina Santiago de Chile: Asociación de Municipalidades de Chile/Universidad Tecnológica Metropolitana, págs. 21-39.

Cravacuore, Daniel (2014) El sistema municipal argentino. Documento presentado en el XI Congreso Chileno de Ciencia Política. Santiago de Chile: Asociación Chilena de Ciencia Política.

Cravacuore, Daniel (2011) "El asociativismo intermunicipal en la Provincia de Buenos Aires (1993 - 2007)”, en D. Cravacuore, Intermunicipalidad y Desarrollo Local. Hacia una teoría común iberoamericana de la intermunicipalidad. Granada (España) Unión Iberoamericana de Municipalistas, págs. 93-121.

Cravacuore, Daniel (2006) “Análisis del asociativismo intermunicipal en Argentina”, en Medio Ambiente y Urbanización 64:3-16.

Cravacuore, Daniel, S. Ilari y A. Villar (2004) La articulación en la gestión municipal: actores y políticas. Bernal, Pcia. de Buenos Aires: Universidad Nacional de Quilmes.

Duarte, Marisa (2002) "El Consenso de Washington y su correlato en la Reforma del Estado en la Argentina: los efectos de la privatización”. En: Más allá del pensamiento único. Hacia una renovación de las ideas económicas en América Latina y el Caribe. CLACSO, Consejo Latinoamericano de Ciencias Sociales, pp143-188. (Buenos Aires).

Esteban, R. y D. Rossi, (2003). Aportes hacia una regionalización posible y necesaria para los municipios de la Provincia de Buenos Aires. Documento presentado en elV Seminario Nacional de la Red de Centros Académicos para el Estudio de Gobiernos Locales. San Fernando (Argentina). 
Fagundez, Patricia (2018) Asociativismo intermunicipal "desde abajo" en la provincia de Buenos Aires (tesis de maestría), Universidad de San Andrés, Buenos Aires (Argentina).

Fagundez, Patricia (2005) Redes Intermunicipales Metropolitanas en Argentina. Un estado de la cuestión desde la perspectiva de políticas públicas. Documento presentado en el VII Seminario de la Red Nacional de Centros Académicos dedicados al estudio de la Gestión en Gobiernos Locales. Universidad Nacional de General Sarmiento/ Instituto Nacional de la Administración Pública.

Iturburu, M. (2000) "Nuevos acuerdos institucionales para afrontar el inframunicipalismo argentino”, en: M. Iturburu y N. REDONDO, comps. Cooperación intermunicipal en Argentina. Buenos Aires: EUDEBA/INAP, págs. 37-68.

Magri, A. y M. Huete (2010) "Gobernando las áreas metropolitanas: gobernanza y gobernabilidad iberoamericanas en perspectiva comparada", en D. Cravacuore y C. Navarro, comps. Gobierno local y relaciones intergubernamentales en Iberoamérica. Las bases formales de los procesos de gobernanza local. Buenos Aires: Miño y Dávila:117-143.

Marchiaro, Enrique (2005) El derecho argentino y lo intermunicipal. Más fortalezas que debilidades. Ponencia presentada en el Seminario La intermunicipalidad, una herramienta para la gobernabilidad y el desarrollo de los territorios en Argentina. Secretaría de Asuntos Municipales de la Nación - Embajada de Francia en Argentina - Federación Argentina de Municipios - Ministerio de Relaciones Exteriores, Comercio y Culto de la Nación. Buenos Aires.

Pírez, Pedro (2008) "Gobernabilidad Metropolitana en Argentina”, en Gustavo Badía y R. Carmona, comps. La Gestión Local en Argentina: situación y perspectivas. Los Polvorines, Pcia. de Buenos Aires: Universidad Nacional de General Sarmiento.

Pírez, Pedro (2005) El desafío de la gobernabilidad metropolitana en la Argentina. Ponencia presentada en VII Seminario Nacional de Centros Académicos dedicados al estudio de la Gestión en Gobiernos Locales. Los Polvorines (Argentina) Universidad Nacional de General Sarmiento - Instituto Nacional de la Administración Pública.

\section{Sitios Web consultados}

http://www.atlasconurbano.info/index.php http://observatorioconurbano.ungs.edu.ar/ http://www.idealquilmes.com.ar/ https://www.indec.gob.ar/ https://www.gba.gob.ar/ http://municipios.unq.edu.ar/ 
https://www.argentina.gob.ar/economia

http://www.rsoconsultora.com.ar/index.php/ar/entrada/index.html

https://metropolitana.org.ar/

https://www.cippec.org/

http://bel.unq.edu.ar/

http://www.estadistica.ec.gba.gov.ar/dpe/index.php

\section{Entrevistas realizadas}

Daniel Cravacuore. Académico, ex funcionario en Florencio Varela y asesor político. Especialista en municipalismo iberoamericano, asociativismo intermunicipal. Participó activamente en el surgimiento y comienzos del COMCOSUR.

Patricia Fagundez. Académica especializada en asociativismo intermunicipal desde abajo. Investigó sobre la RMN y el COMCOSUR.

Walter Romero. Docente. Ex funcionario a cargo de la Secretaría de Planificación Estratégica de la Municipalidad de Avellaneda con participación en el COMCOSUR.

Alberto Esteban. Ex funcionario de la Municipalidad de San Fernando. Tuvo participación en la RMN.

\section{Cómo citar este artículo:}

Rubino, Fernando J. (2021) “La intermunicipalidad en el AMBA. Análisis de las experiencias de asociativismo Región Metropolitana Norte y Consorcio de Municipios del Conurbano Sur”. Revista Perspectivas de Políticas Públicas vol 10 № 20: 271-298 